NBER WORKING PAPER SERIES

A SIMPLE ACCOUNT OF THE BEHAVIOR
OF LONG-TERM INTEREST RATES

John Y. Campbell

Robert J. Shiller

Working Paper No. 1203

NATIONAL BUREAU OF ECONOMIC RESEARCH

1050 Massachusetts Avenue

Cambridge, MA 02138

September 1983

The research reported here is part of the NBER's research program in Financial Markets and Monetary Economics. Any opinions expressed are those of the authors and not those of the National Bureau of Economic Research. 


\title{
A Simple Account of the Behavior of Long-Term Interest Rates
}

\begin{abstract}
Recent empirical research on the term structure of interest rates has shown that the long-term interest rate is well described by a distributed lag on short-term interest rates, but does not conform to the expectations theory of the term structure. It has been suggested that the long rate "overreacts" to the short rate. This paper presents a unified taxonomy of risk premia, or deviations from the expectations theory. This enables the hypothesis of overreaction to be formally stated. It is shown that, if anything, the long rate has underreacted to the short rate. However, the independent movement of the long rate is primarily responsible for the failure of the expectations theory.
\end{abstract}

John Y. Campbe11 Cowles Foundation for Research in Economics Box 2125 Yale Station New Haven, CT 06520 (203) 436-4433
Robert J. Shiller Cowles Foundation for Research in Economics Box 2125 Yale Station New Haven, CT 06520 (203) $432-4134$ 


\section{Introduction.}

To a first approximation, long-term interest rates behave like short-term interest rates. For example, the yields on twenty year Treasury bonds and on one month Treasury bills tend to peak and to bottom out together. Thus people often speak of "the level of interest rates" without specifying maturity.

The spread between long rates and short rates tends to be unusually small or even negative when short rates are high relative to the experience of the last few years. Modigliani and Sutch showed that the relation between long and short rates can be well described by expressing the long rate as a five-year distributed lag of short rates, with the coefficients summing to about one and with substantial weight on the current short rate. Recent experience upholds this characterization except that the distributed lag has become shorter (Ando and Kennickell). Equivalently, the spread between long and short rates is well explained by current and lagged short rates, with approximately equal and opposite coefficients on the current rate and the sum of lagged rates. (See table 1 , row 1 ).

This moving average relation could be consistent with the simple expectations theory of the term structure, if investors look to the recent past to form expectations about future interest rates. Whether such expectations are rational depends on the time series properties of short-term interest rates. Depending on the policy regime and its implications for the movements of short rates, the observed distributed lag might correspond to a rational expectations theory of the term structure, or a theory of overreaction or underreaction of long rates 
to short rates, relative to the predictions of the rational expectations model. Experimental psychologists, such as Tversky and Kahneman, claim to have shown that people tend to overreact in their expectations to evidence which seems superficially to be relevant, even after experience should have convinced them otherwise. This suggests that there might be policy regimes where the long rate overreacts to temporary movements in short rates. Of course, any such "overreaction" might also be reconciled with the theory of finance if certain covariances change with the short rate.

A look at the data suggests an abrupt policy shift starting with the Fed's new operating procedures in October 1979. We concentrate here on the policy regime which prevailed between the 1951 Treasury accord and 1979. Modigliani and Shiller claimed that for the early part of the period the observed distributed lag was approximately consistent with the time series properties of the short rate given a simple expectations model, and Sargent was unable to reject this hypothesis with a likelihood ratio test in a vector autoregression. However, more recent work has cast doubt on the notion that the simple rational expectations model of the term structure is adequate even as a first approximation to the behavior of interest rates. It was shown by Shiller that when long-term interest rates are unusually high relative to short rates they then tend to fall rather than rise as predicted by the expectations theory. Shiller, Campbell and Schoenholtz showed that when six-month bill rates are higher than three-month bill rates there is no tendency for the three-month bill rate to rise subsequently. Hansen and Sargent were able to reject the rational expectations 
theory at the $0.5 \%$ level with a likelihood ratio test on postwar U.S. data when an additional restriction involving the current long-term interest rate was added to Sargent's earlier formulation.

These results might be summarized as finding that the behavior of long-term interest rates is dominated by a "risk premium" which is so variable as to swamp out expectations in determining the slope of the term structure. The phrase "risk premium" has been defined in various ways in the term structure literature. We turn next to a discussion which will clarify the relations among these definitions. This enables us to state more formally the hypotheses that long rates overreact or underreact to short rates, and it provides a framework in which we characterize interest rate behavior. 
II. "Well-Tempered" Definitions of Risk Premia.

We make use here of approximations to holding-period yields and forward rates which are obtained by linearizing the exact expressions around the coupon rate on a long-term bond. These approximations were developed by Shiller, Campbell and Schoenholtz who also investigated their accuracy. Such preliminary linearization is essential if risk premia are to be defined in a coherent way, that is so that Jensen's Inequality problems do not make their interrelationships extremely complicated. The analogy with the reconciliation of different keys in music leads us to call our system a "well-tempered" one.

We chose our definitions to facilitate comparison with bond yields as commonly quoted. Bonds issued with less than a year to maturity commonly carry no coupons, but longer term bonds generally pay coupons which bring their sale price near par. It is natural then to define the five year ahead ten year forward rate, for example, as the yield on a ten year coupon bond to be purchased at par five years hence. Such an asset can be constructed today as a portfolio of bonds with maturities up to fifteen years. Similarly, the five year holding return on a fifteen year bond is the yield to maturity on buying the fifteen year bond, receiving its coupons, and selling it five years hence (when it is a ten year bond). The fifteen year holding yield on a five year bond is the yield to maturity on an investment in three consecutive five year coupon bonds, reinvesting principal (i.e. rolling over the five year bonds) but receiving coupons.

The linear approximation to the j-period holding yield on an iperiod bond is : 


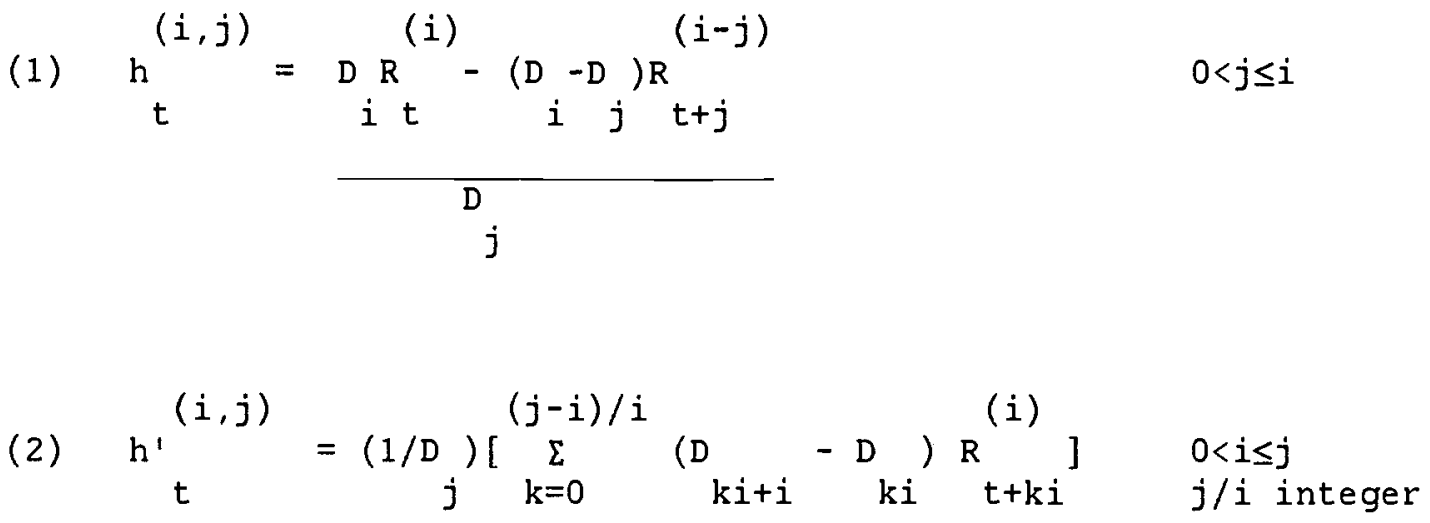

The linear approximation to the n-period ahead m-period forward rate is :

(3) $f_{t}^{(n, m)}=\frac{D R_{m+n} R^{(m+n)}-D R^{(n)}}{D+n-D}$

(i)

$\mathrm{R}_{\mathrm{t}}=$ yield to maturity on an $i$-period bond
$\mathrm{D}_{i}=(1-\mathrm{g}) /(1-\mathrm{g}), \mathrm{g}=1 /(1+\overline{\mathrm{R}}), \overline{\mathrm{R}}=$ coupon rate

$D_{i}$ is the "duration" of an i-period bond selling at par with coupon $\bar{R}$, as defined originally by Macaulay. Duration is intended as a better measure than maturity of how "long" a bond is. It takes account of the fact that bonds with coupons derive much of their value from payments which are made earlier than maturity. Thus for bonds with coupons, $D_{0}=0, D_{i+1}-D_{i}=g^{i}$, so $D_{i}<i$ for $i>1$. For pure discount bonds, $\bar{R}=0$ and duration and maturity are the same. 
The simple expectations theory of the term structure, with no al-

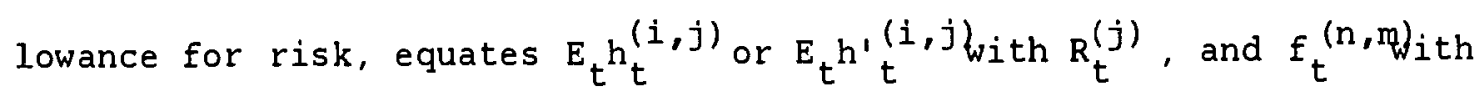
$E_{t} R_{t+n}^{(m)}$ : Risk premia are deviations from this theory, which can be written either as differences between expected holding returns and yields, or as differences between forward rates and expected spot rates. We denote the former as $\left.\phi^{(i, j)} j \leq i\right)$ or $\left.\phi^{(i, j)} j \geq i\right)$, and the latter as $\psi^{(\mathrm{n}, \mathrm{m})}$ Then we have the holding period risk premium:

$$
\phi_{t}^{(i, j)}=E h^{(i, j)}
$$ $\mathrm{t}$ $j \leq i$

the rolling risk premium:

$$
\phi_{t}^{(i, j)}=E h^{\prime} t^{(i, j)}-R_{t}^{(j)}
$$

$j \geq i$

and the forward rate risk premium:

(6)

$$
\psi_{t}^{(n, m)}=f_{t}^{(n, m)}-E R_{t}^{(m)}
$$

$\phi, \phi^{\prime}$ and $\psi$ all appear in the existing literature on the term structure. Our well-tempered formulation allows us to derive simple linear relationships among them. First, we can substitute (1) and ( 3 ) into (4) and (6) to show that

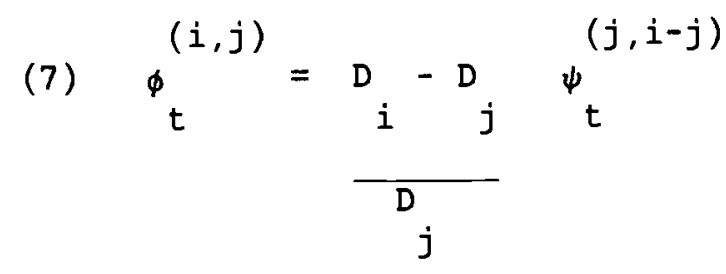

$$
\psi_{t}^{(n, m)}=\frac{D_{n}}{D_{m+n}-D_{n}}{ }_{t}^{(m+n, n)}
$$


Secondly, we can rearrange equation (3) so that it expresses the j-period bond rate as a weighted average of forward rates of maturity $i$, with weights equal to those in equation (2). It is immediate that

$$
\phi_{t}^{(i, j)}=-(1 / D)\left[\sum_{j=0}^{(j-i) / i}\left(D \underset{k i+i}{\sum_{k i}}-\psi_{t}^{(k i, i)}\right] \quad 0<i \leq j\right.
$$

Finally, we can rearrange equation (1) so that it expresses the $j$-period bond rate at time $t$ as a function of the $i$-period holding return on a $j$-period bond and the (j-i)-period bond rate at time $t+i$. By recursive substitution, we obtain the following expression:

$$
\text { (9) } \phi_{t}^{(i, j)}=(-1 / D)\left[\sum_{k=0}^{(j-i) / i}\left(D \underset{k i+i}{-D}{ }_{k i}\right) E \phi_{t+k i}^{(j-k i, i)}\right]
$$

A natural interpretation of the notion that long rates overreact to short rates is that long bonds are a "good investment" when the short rate is high. In other words, the returns on long bonds over some holding period tend to be higher than those predicted by the expectations theory when the short rate is high: the holding period or rolling risk premium is positively correlated with the short rate. ${ }^{1}$ In

1 Mankiw and Summers interpreted overreaction as the hypothesis that the long rate behaves according to the expectations model for a bond of shorter duration. This definition is consistent with ours, in that if long rates overreact in Mankiw and Summers' sense, and if the time series process for short rates is stationary, then the holding period risk premium is positively related to the short rate. The reverse is not necessarily true, however. We note that incorrect duration, whether too short or too long, could never explain the observation that the slope of the term structure gives wrong signals about the future path of interest rates. 
the next section we examine the relation between the one month excess holding return on a twenty year bond, and the one month Treasury bill rate. We do not calculate the twenty year excess return on a twenty year bond, which includes the rolling risk premium, since we have only just over twenty years of data. However, we study the rolling risk premium indirectly by conducting an ARIMA analysis of the one month bill rate. 
III. The Behavior of Risk Premia.

We can estimate $\phi_{t}$ by regressing the excess return $h_{t}^{(i, j)}-R_{t}^{(j)}$ on variables in the information set at $t$. The excess return is just $\left(D_{i} / D_{j}-1\right)$ times the forward-spot rate difference $f_{t}^{(j, i-j)}-R_{t+j}^{(i-j)}$, so equivalent results are obtained with this dependent variable.

Kessel ran regressions of forward-spot rate differences at the short end of the term structure on the short interest rate, and concluded that the forward rate premium was positively related to the short yield. Such a correlation could be taken to mean that long interest rates overreact to short rates. However, our work with more recent data shows that the effect of the short rate is, if anything negative (table 1 , row 2). But the short rate has very little explanatory power; it is rather the spread between long and short rates (table 1, row 3 ) which explains excess holding returns. This is a reflection of the perverse behavior of the slope of the term structure in predicting future interest rates. ${ }^{2}$

There has been an uptrend in interest rates since Kessel's sample. This suggests an alternative overreaction or underreaction hypothesis that risk premia may be explained in terms of the difference between the short rate and a moving average or distributed lag of short rates. In fact, our results so far would seem to suggest just this, for by row 1 of table 1 the long-short spread which explains excess returns is itself well described as a distributed lag on short

2 We note here the curious fact that excess returns of common stock over short debt also bear a significant positive relation to the long-short spread (Campbell). This observation suggests that risk premia on different assets move together. 
rates. The coefficients lead us to expect that the risk premium is high when the short rate is low relative to recent experience. Nevertheless, when the excess return is regressed directly on current and lagged short rates (table 1 row 4 ), the point estimates are statistically insignificant. This evidence is not inconsistent with rational forecasting in the $1955-79$ period. We note however that when the sample is extended to the end of 1982 the coefficient on the current short rate becomes negative and significant at the $9 \%$ level, while the sum of the lag coefficients is positive and significant at the $7 \%$ level. This could be taken to imply that long rates have underreacted to short rates. ${ }^{3}$

Another way to examine this issue is to conduct an ARIMA analysis of the benavior of short rates. Shiller's volatility analysis suggested that nonstationarity of interest rates might be necessary to justify the behavior of long rates; we assumed this conclusion and used monthly data over the period 1955-79 to estimate an ARIMA $(1,1,1)$ process for the 1 -month bill rate. This specification has the important advantage of being time consistent, that is independent of the measurement interval. It implies that the long-short spread under the rational expectations theory of the term structure should be a function of current and lagged short rates, with the influence of lagged short rates declining geometrically at a rate equal to the MA parameter, and with the sum of the coefficients on lagged short rates equal to the negative of the coefficient on the current short rate. We found that the likelihood function was very flat, but was maximized by

3 We observe a similar underreaction in postwar British data (Shiller, data set 5). 
the model $(1-0.950 \mathrm{~L}) \Delta \mathrm{R}_{\mathrm{t}}=(1-0.975 \mathrm{~L}) \mathrm{u}_{\mathrm{t}}$. With these parameter values the rational expectations model implies that the coefficients in table 1 , row 1 should be -0.47 and +0.47 respectively, with a very slow decay within the distributed lag. The Modigliani-Sutch distributed lag is roughly consistent with this, but has a more highly negative coefficient on the current short rate. This suggests that the rolling risk premium tends to be high when the short rate is low relative to its recent history.

When the short rate and its distributed lag are included in a regression together with the long-short spread (row 5 of table 1), we find that both become significant, and the coefficient on the spread triples. The fitted values in this regression look something like a multiple of the residuals from row 1, suggesting that the significance of the current and lagged short rates is due to the regression's trying to purge the long-short spread of the component which is explained by current and lagged short rates. When the fitted value and residual from row 1 are included separately, only the residual is significant (table 1 row 6 ). It is also the residual which in the 1955-79 sample accounts for the violation, noted by shiller, of variance restrictions on holding period yields. When the sample is extended to 1982, however, both the fitted value and the residual explain excess holding returns and violate the variance restrictions.

We see then that holding period and rolling risk premia have if anything been negatively related to short rates, suggesting that long rates if anything have underreacted to short rates. If long rates had been a distributed lag on short rates, with a somewhat larger coeffi- 
cient on the current short rate and smaller coefficients on lagged short rates, then excess holding returns on long bonds would have been less predictable than they in fact were. But this sort of underreaction was not primarily responsible for the failure of the expectations theory of the term structure. The independent movement of the long rate also violated the restrictions of the theory. In the 1955-79 period, it was that smaller part of the spread between long and short rates which was not explained by current and lagged short rates that caused excess volatility in holding period yields and destroyed the predictive power of the term structure. 
Ando, Albert and Arthur Kennickell, "A Reappraisal of the Phillips Curve and the Term Structure of Interest Rates", unpublished paper, University of Pennsylvania, 1983.

Campbell, John Y., "Stock Returns, the Term Structure and Inflation", unpublished paper, Yale University, 1983.

Hansen, Lars Peter and Thomas J. Sargent, "Exact Linear Rational Expectations Models: Specification and Estimation", Federal Reserve Bank of Minneapolis Staff Report, 1981.

Kessel, Reuben A., "The Cyclical Behavior of the Term Structure of Interest Rates", National Bureau of Economic Research Occasional Paper 91, 1965.

Macaulay, Frederick, Some Theoretical Problems Suggested by the Movements of Interest Rates, Stock Prices and Bond Yields in the United States Since 1856, National Bureau of Economic Research, $\overline{\text { New York, }}$ $\overline{19} 3 \overline{8}$.

Mankiw, N. Gregory and Lawrence H. Summers, "Do Long-Term Interest Rates Overreact to Shorc-Term Interest Rates?", Council of Economic Advisers, 1983.

Modigliani, Franco and Robert J. Shiller, "Inflation, Rational Expectations and the Term Structure of Interest Rates", Economica Vol. $40 \mathrm{pp} .12-43,1973$.

Modigliani, Franco and Richard C. Sutch, "Debt Management and the Term Structure of Interest Rates: An Empirical Analysis of Recent Experience", Journal of Political Economy Vol. 75 pp. 569-589, 1967.

Sargent, Thomas J., "A Note on Maximum Likelihood Estimation of the Rational Expectations Model of the Term Structure", Journal of Monetary Economics Vol. 5 No. 1 pp. 133-143, 1979.

Shiller, Robert J., "The Volatility of Long-Term Interest Rates and Expectations Models of the Term Structure", Journal of Political Economy Vol. 87 pp. 1190-1219, 1979.

Shiller, Robert J., John Y. Campbell and Kermit L. Schoenholtz, "Forward Rates and Future Policy: Interpreting the Term structure of Interest Rates", Brookings Papers on Economic Activity 1983:1 pp. 173-217, 1983.

Tversky, Amos and Daniel Kahneman, "Judgment Under Uncertainty: Heuristics and Biasses", Science Vol. 185 pp. 1124-1131, 1974. 


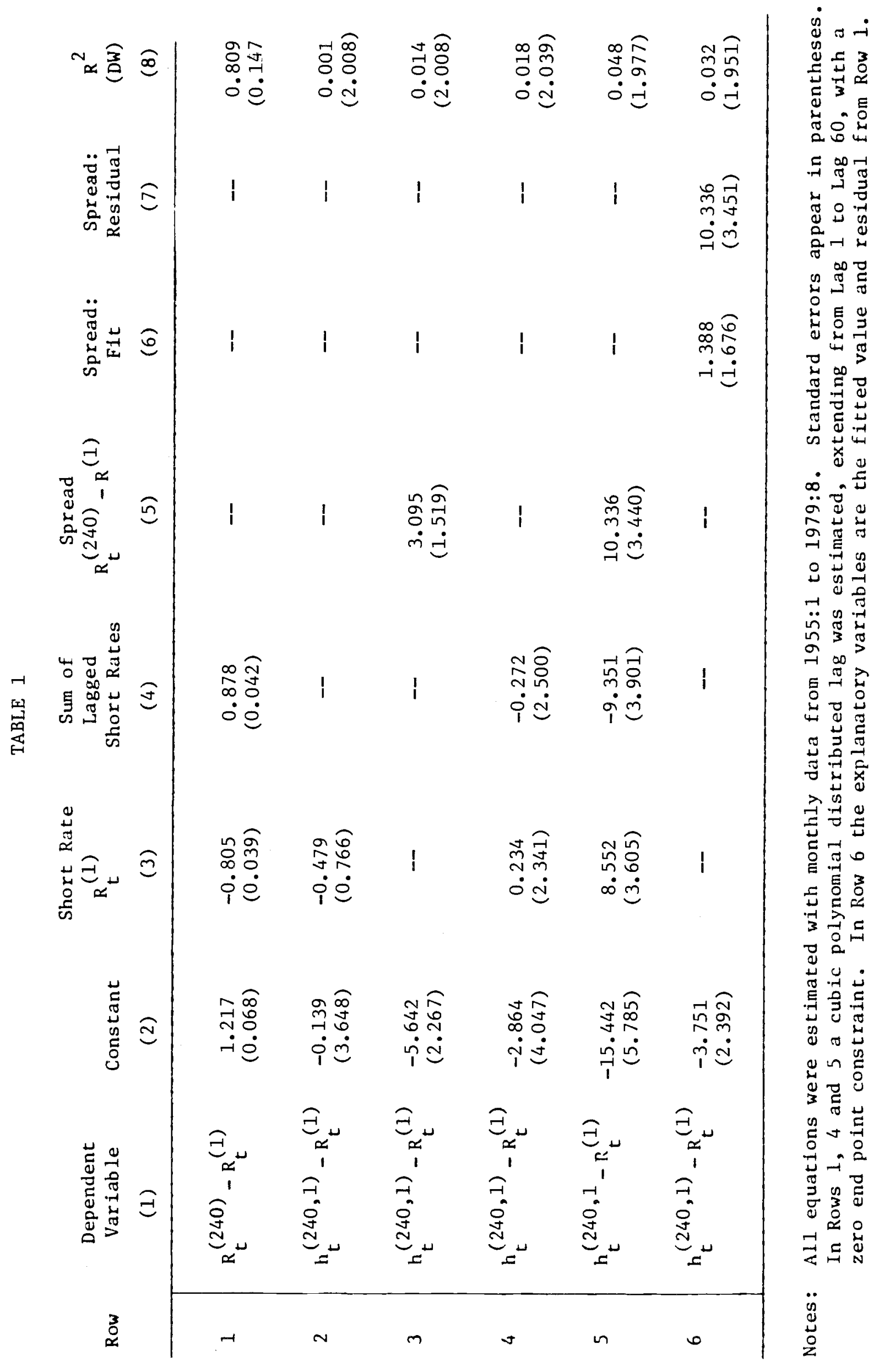




\title{
A Simple Account of the Behavior of Long-Term Interest Rates: \\ Data Appendix
}

\author{
CONTENTS
}

Table A.1, regressions of Table 1 for the sample period 1955:1-1982:12

Table A.2, regressions of Table 1 for Shiller (1979) data set 非 (U.S. quarterly data $1966: 1-1977: 2$ ).

Table A.3, regressions of Table 1 for Shiller (1979) data set 非 (British quarter1y data 1961:1-1977:2).

Figure 1, 1ong and short interest rates, plotted quarterly, 1955:1-1979:3.

Figure 2, demeaned spread between long and short rates and residual from Table 1, row 1, plotted quarterly 1955:1-1979:3.

Description of sources and construction of data.

Printout of data used in Table 1 (long rate, short rate and excess holding return). 


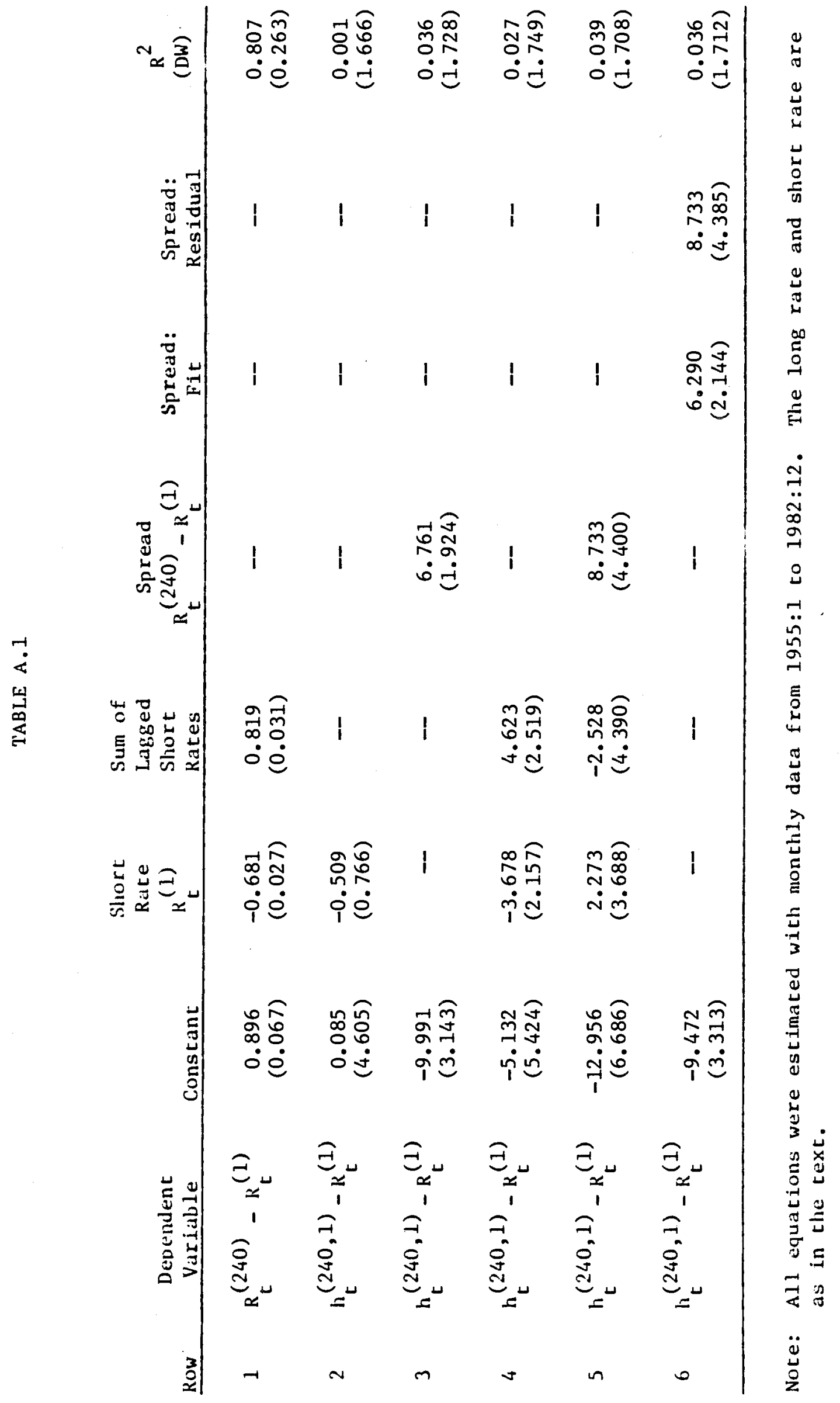




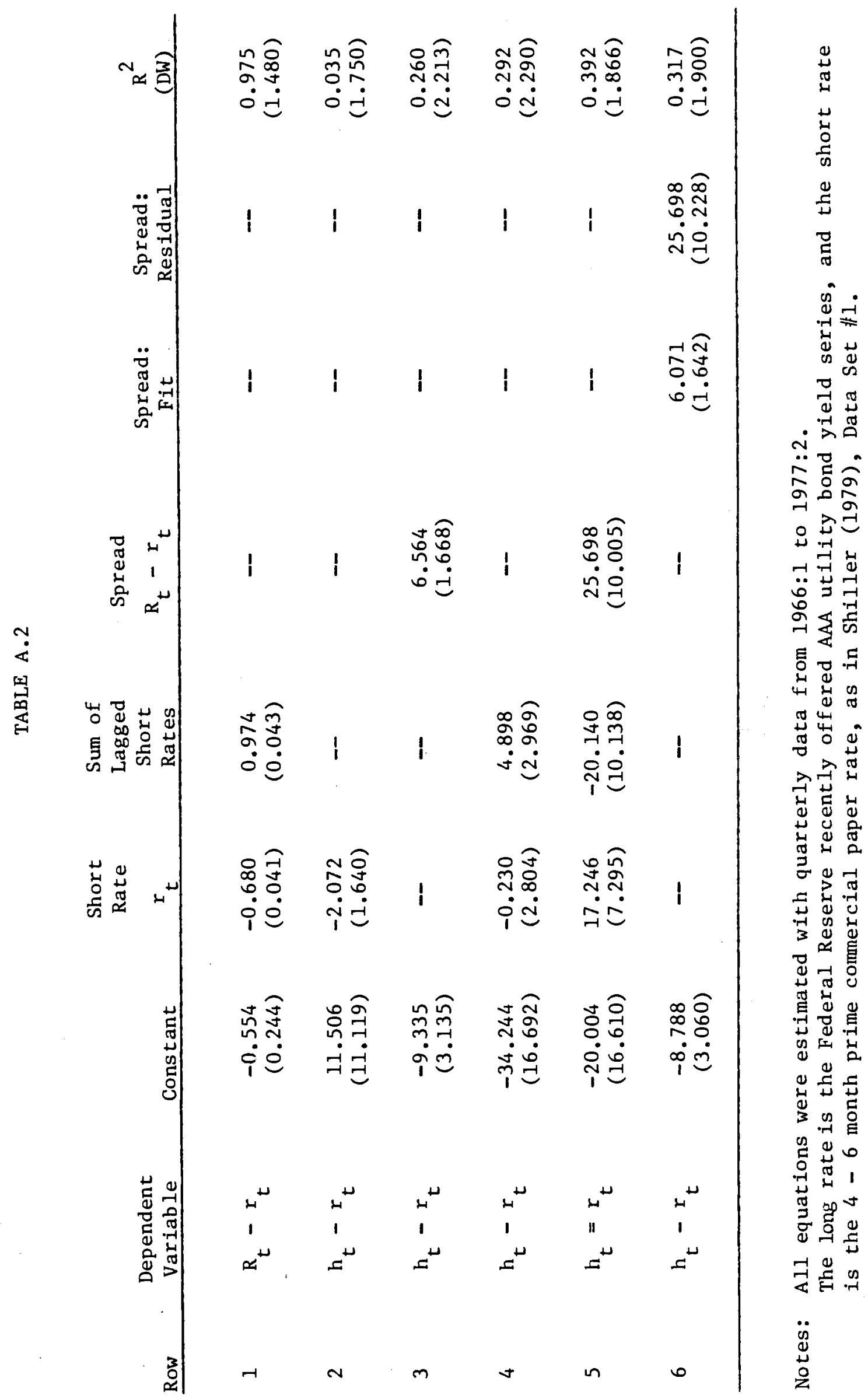




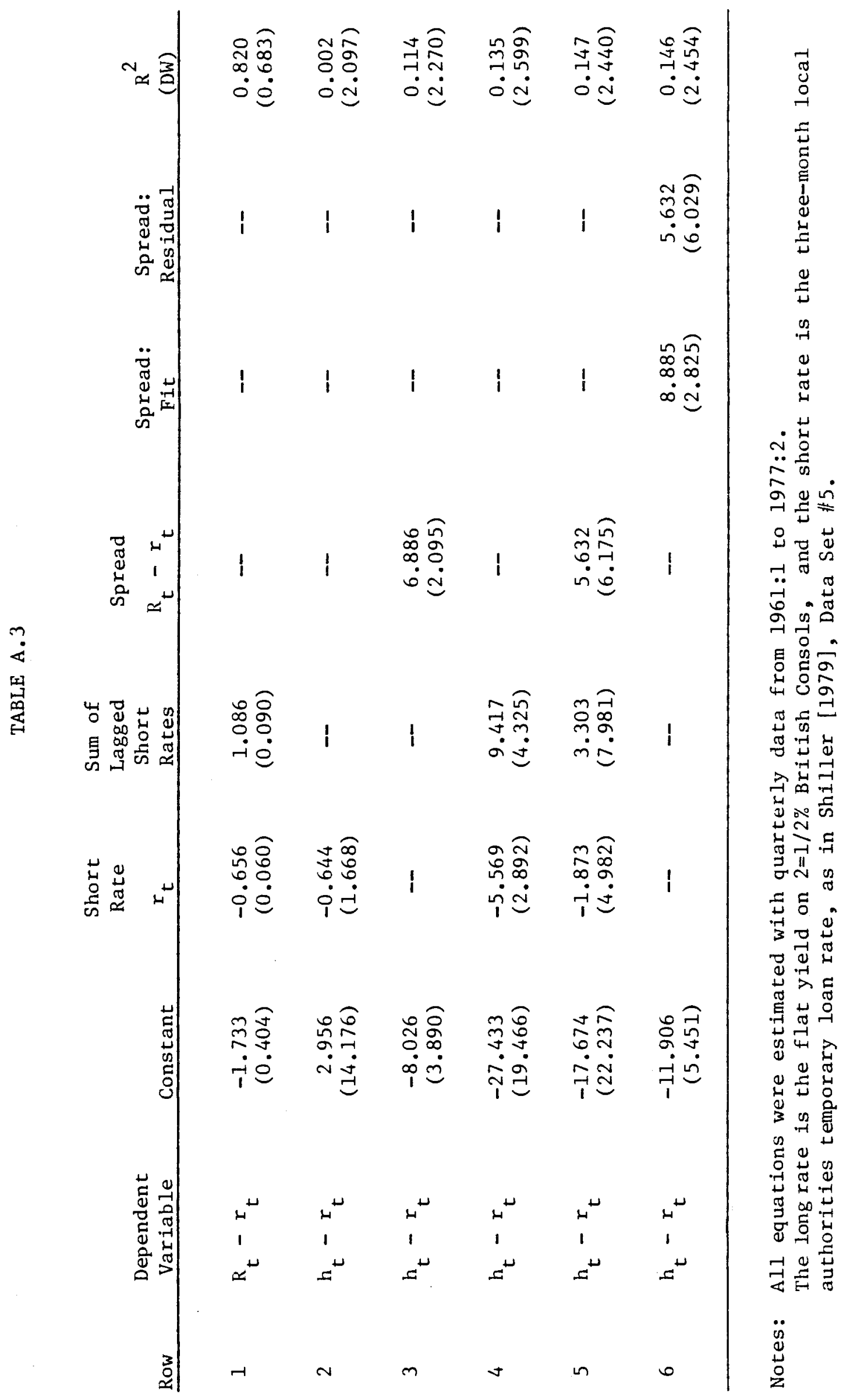




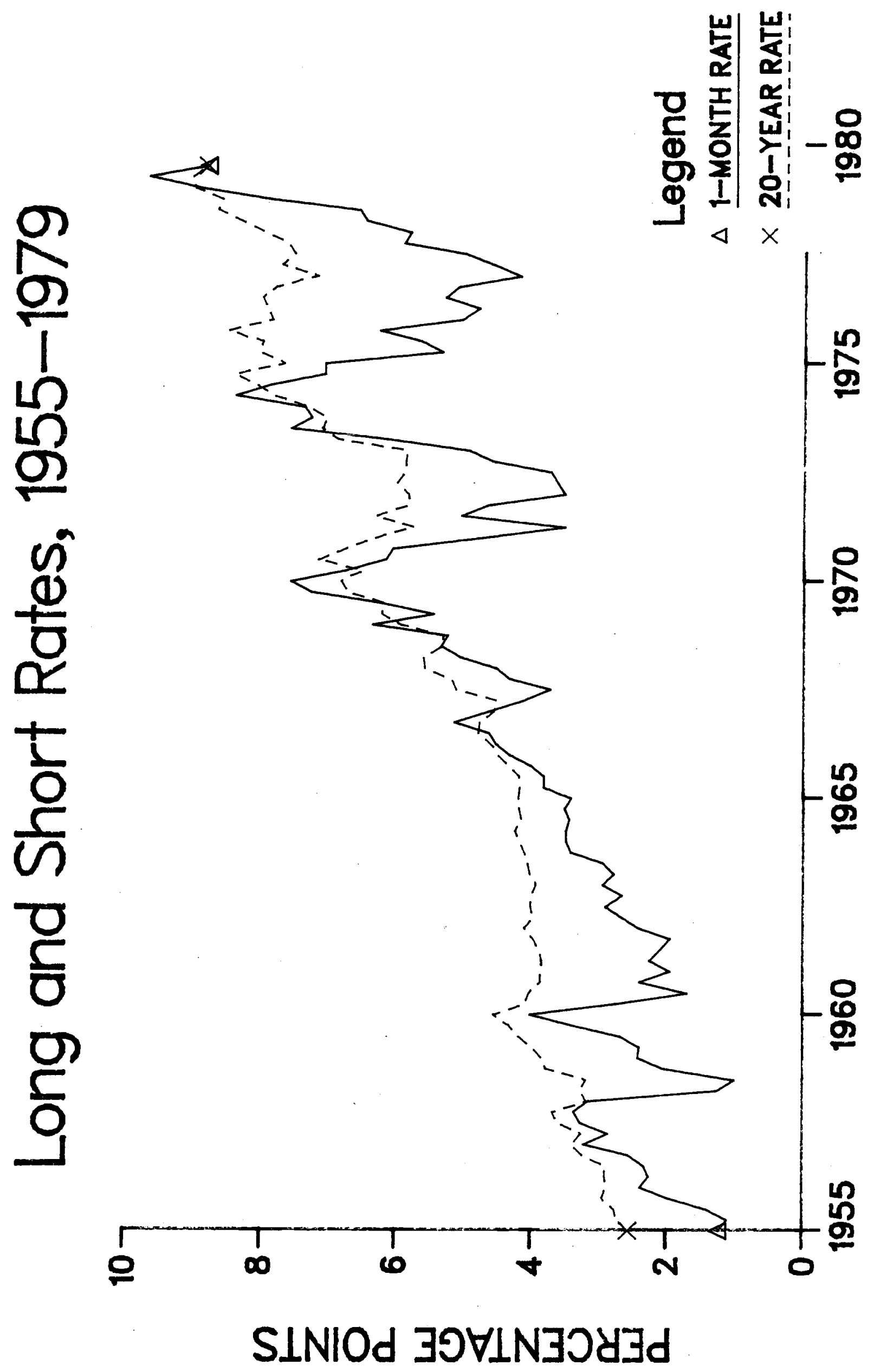



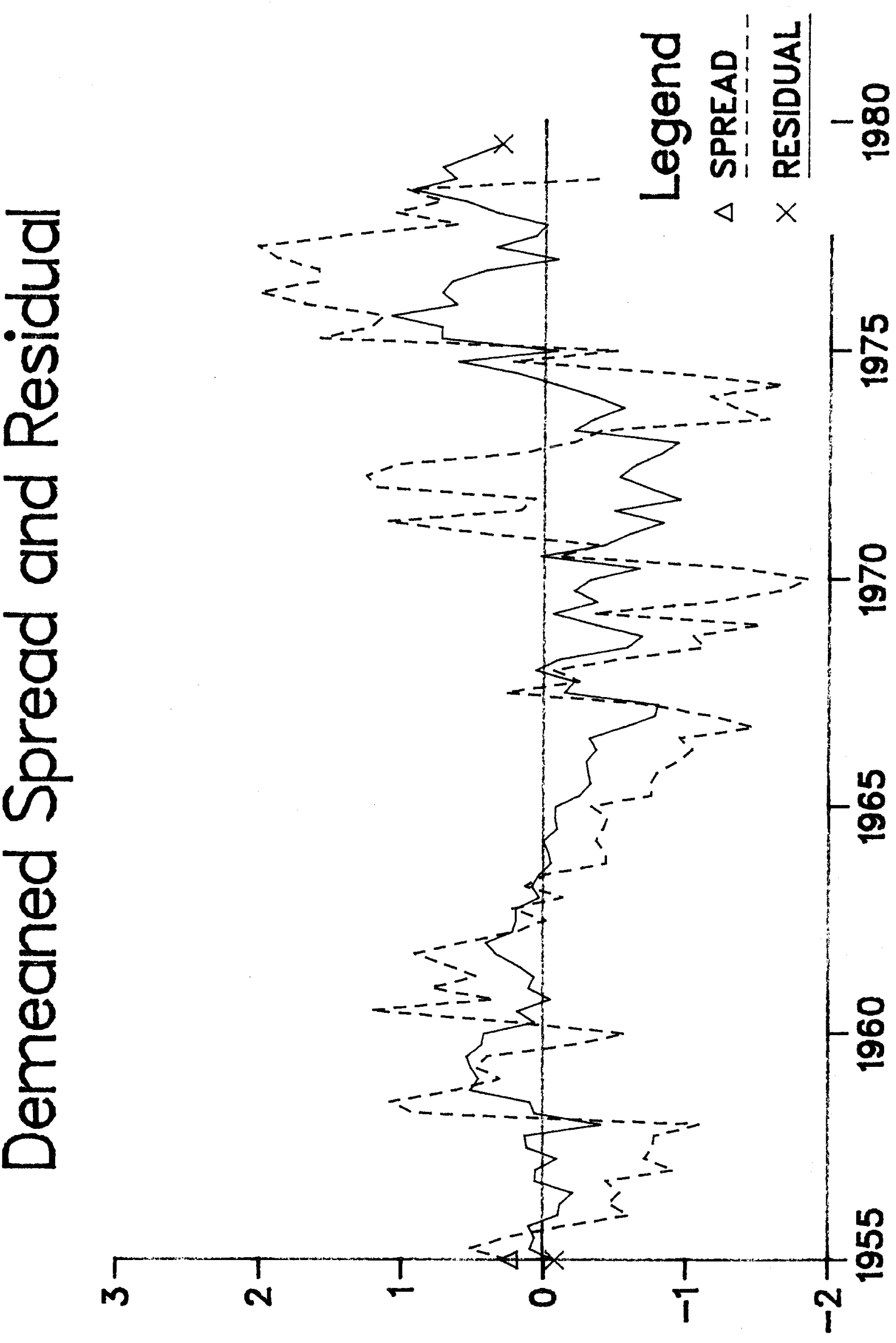

SINIOd $\exists$ JINIJOY $\exists d$ 


\section{Data Sources}

Salomon Brothers' Analytical Record of Yields and Yield Spreads gives point sampled Treasury bill rates and bond yields monthly from 1950:1 to the present.

The 20-year bond yield has been quoted at the first of each month since 1959:1, while the 1-month Treasury bill rate has been quoted at the first of the month since 1964:1. Before these dates, rates were quoted at the middle of each month.

First of month Treasury bill rates are available from the Treasury Bulletin.

The data used in the paper are aligned as follows:

Treasury bill rate: 1950:2 - 1958:12 middle of previous month (Salomon Brothers) 1959:1 - 1963:12 first of month (Treasury) 1964:1 - 1982:12 first of month (Salomon Brothers)

Treasury bond rate: 1950:2 - 1958:12 middle of previous month (Salomon Brothers) 1959:1 - 1982:12 first of month (Salomon Brothers)

The transition from mid-month to first of month data does not distort the calculated holding period yield except in 1958:12.

Treasury bill rates were converted from discount basis to bond-equivalent yield basis using the formula

$$
\mathrm{R}^{(1)}=\mathrm{D} /(1-\mathrm{D} / 1200) \text {, where } \mathrm{D} \text { is the discount rate. }
$$

Holding period yields were calculated using a duration for 20 year bonds of 152.5 months, or approximately $12 \frac{1}{2}$ years. 
Sample 1950.2.-1382.12.

Number or Observations =

$\mathbf{R} 1$

$0 \quad \mathrm{R} 240$

395.

0 EH $2101 \quad 0$

$\begin{array}{rrrr}1950.2 . & 1.1010 & 2.2600 & -3.3847 \\ 1950.3 . & 1.1411 & 2.2900 & -6.4243 \\ 1950.4 . & 1.1210 & 2.3400 & -1.8103 \\ 1950.5 . & 1.1711 & 2.3600 & -1.3403 \\ 1950.6 . & 1.6523 & 2.3500 & -2.3014 \\ 1950.7 . & 1.2513 & 2.4000 & -3.3953 \\ 1950.8 . & 1.1711 & 2.4300 & 1.2588 \\ 1950.9 . & 1.1812 & 2.4300 & 1.2488 \\ 1950.10 . & 1.3215 & 2.4300 & -.40593 \\ 1950.11 . & 1.3315 & 2.4400 & 1.1085 \\ 1950.12 . & 1.3615 & 2.4400 & 1.0784\end{array}$




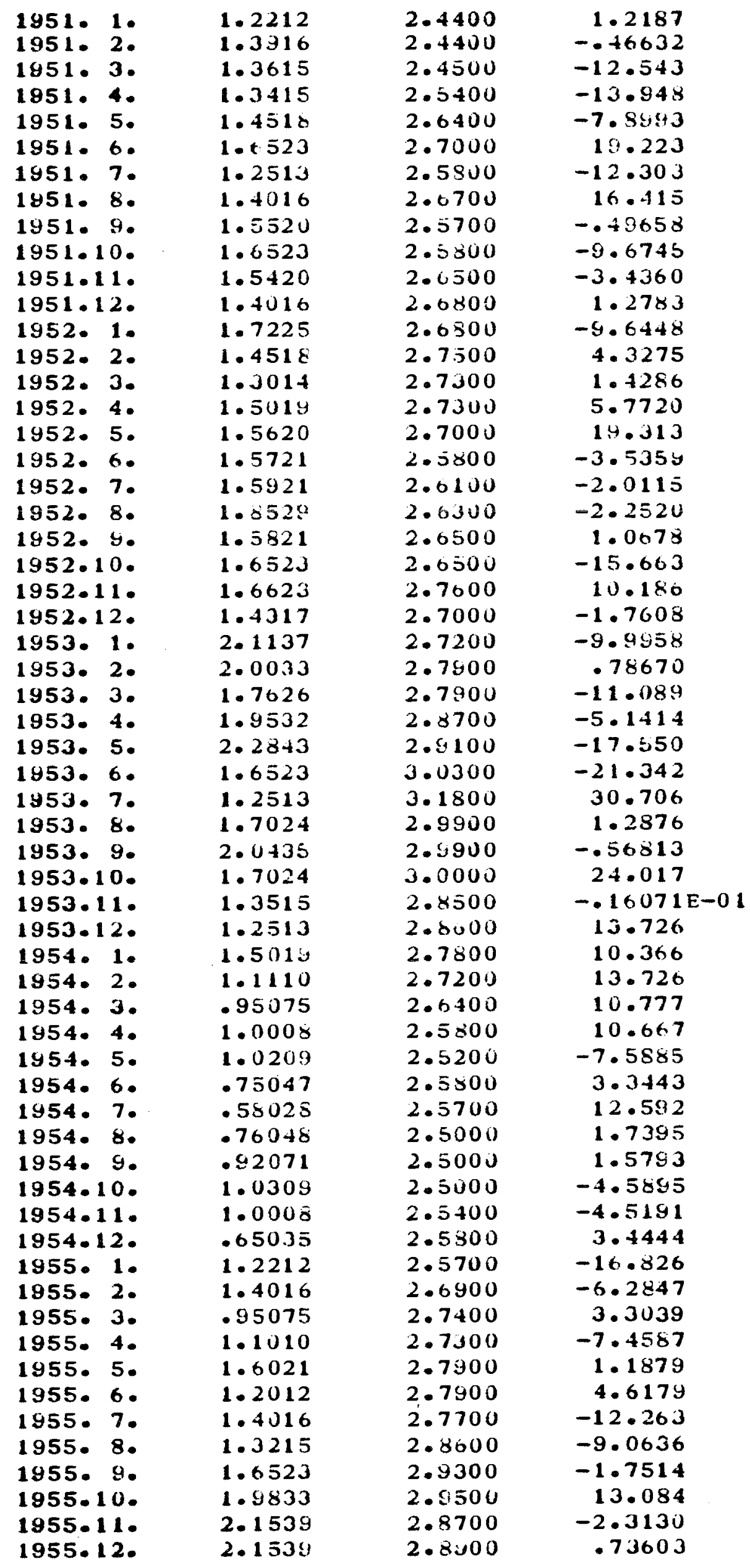




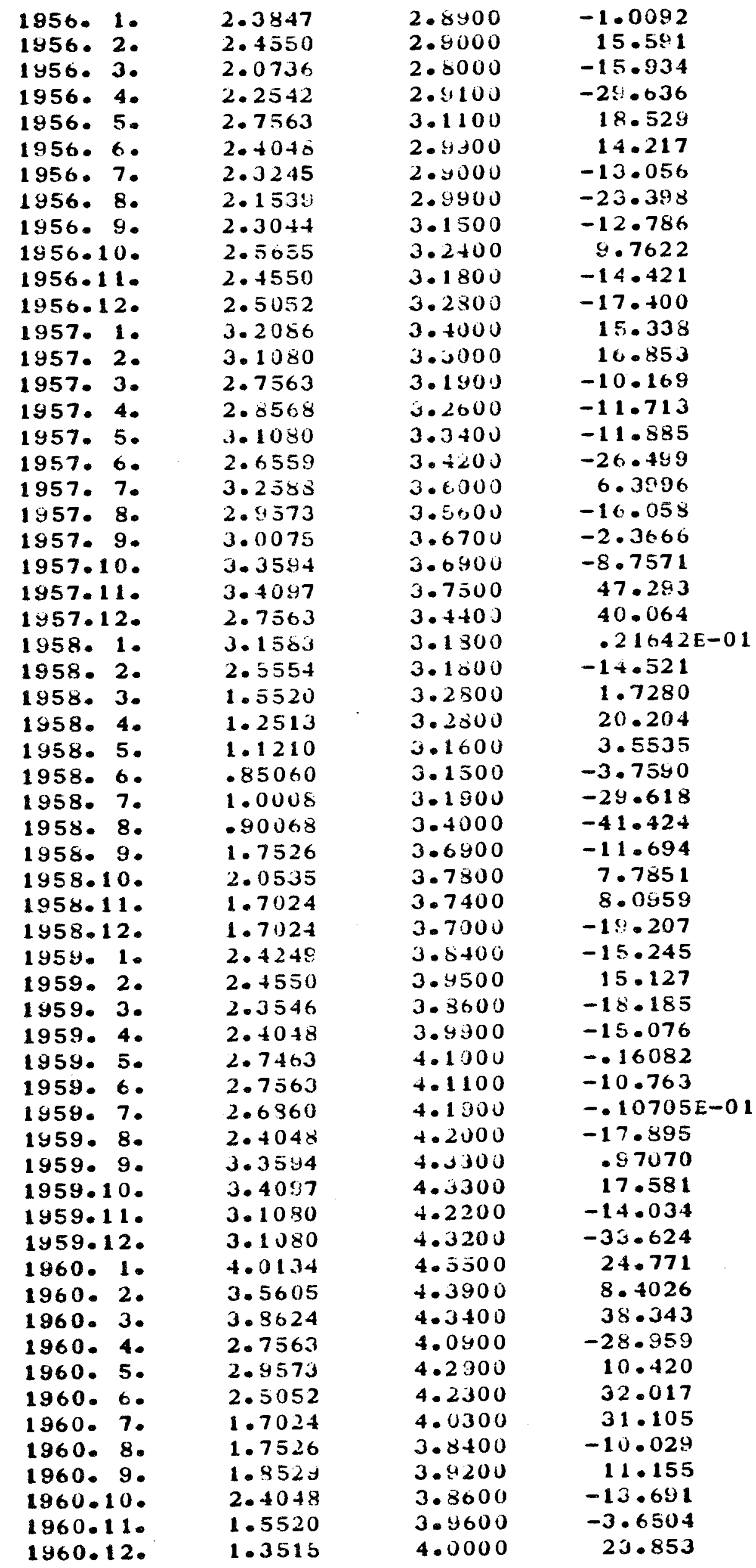




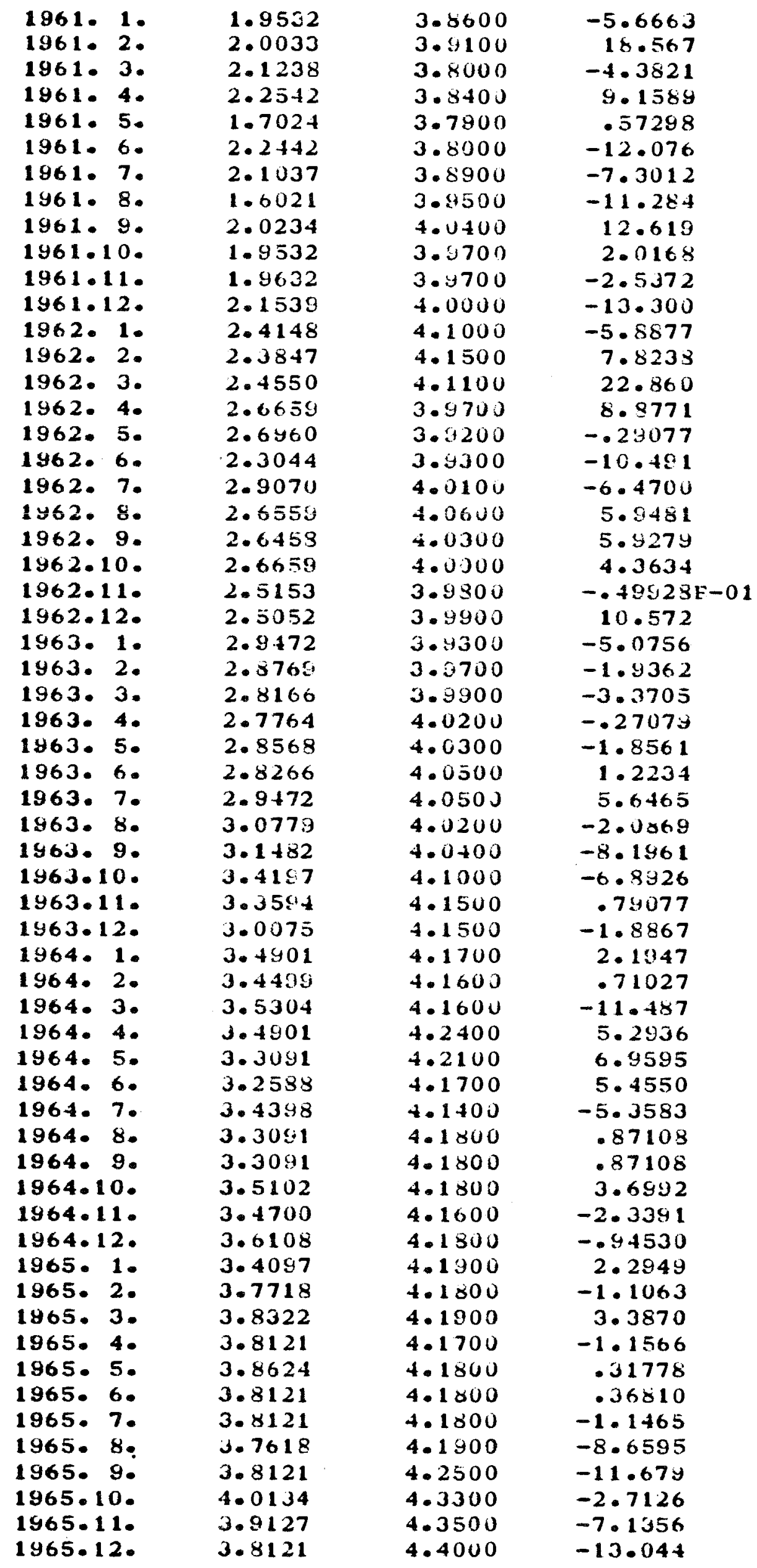




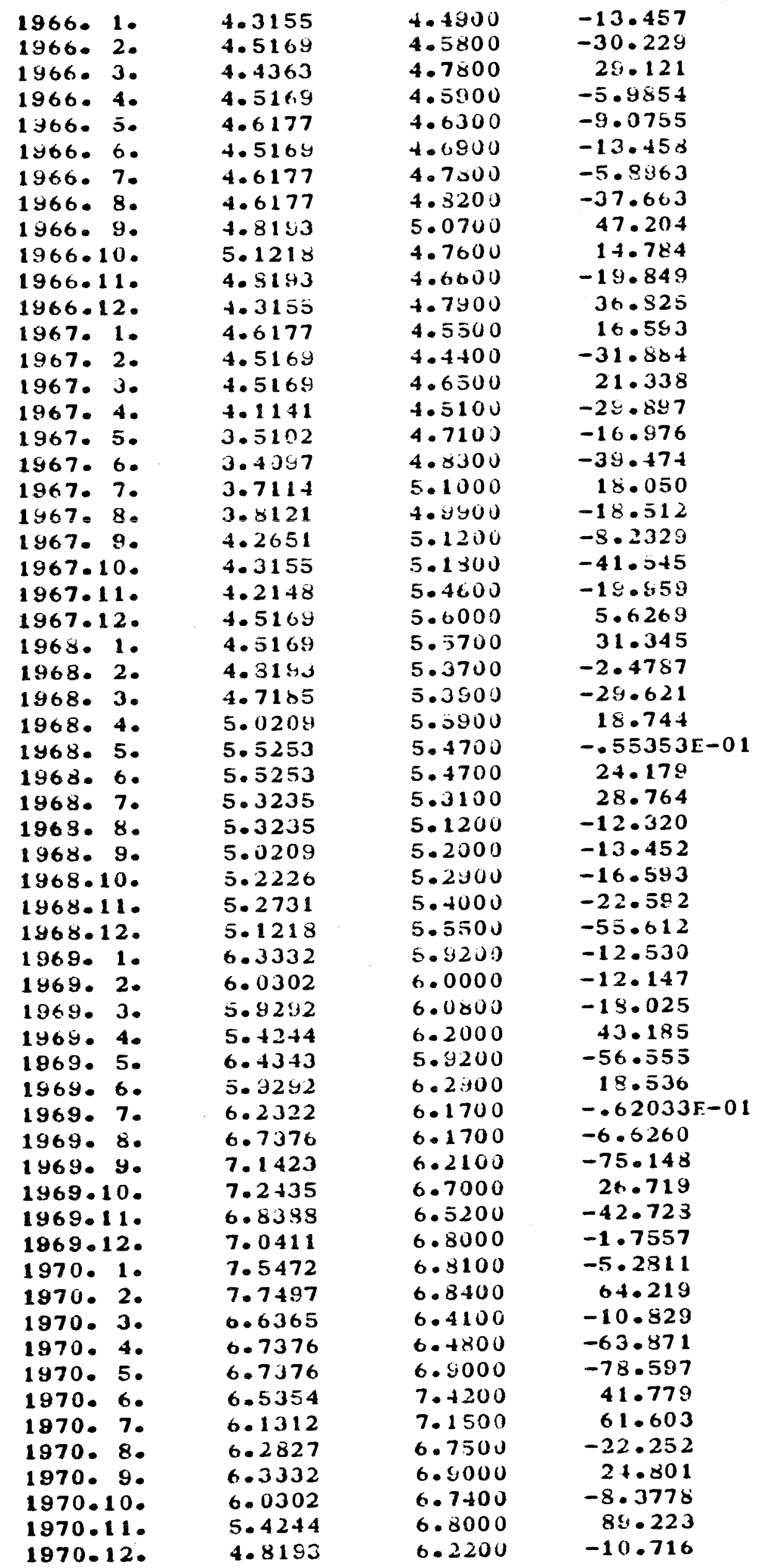




\begin{tabular}{|c|c|c|c|}
\hline $\begin{array}{l}1971.1 . \\
1871.20\end{array}$ & $\begin{array}{l}4.7185 \\
4.2148\end{array}$ & $\begin{array}{l}6.3000 \\
5.9700\end{array}$ & $\begin{array}{r}51.564 \\
-18.449\end{array}$ \\
\hline 1971.3 & $3.35: 44$ & 6.1100 & 60.306 \\
\hline 1971.4 & 3.5102 & 5.7300 & $-35 \cdot 645$ \\
\hline 1971. & 3.9127 & 5.9800 & -20.652 \\
\hline 1971. & 4.3155 & 6.1300 & -23.934 \\
\hline 1971. & 5.0209 & 6.3000 & 1.2789 \\
\hline 1971. & 5.2226 & 6.3000 & 55.604 \\
\hline 1971.9 & 4.6177 & $5.4+00$ & 22.527 \\
\hline 1971.10 & 4.6177 & 5.8000 & 8.7556 \\
\hline 1971.11. & 4.1644 & 5.7500 & $-4 \cdot 4730$ \\
\hline 1871.12. & 4.0134 & 5.7900 & -1.2526 \\
\hline 1972.1 & 3.5102 & 5.3100 & $-11 \cdot 332$ \\
\hline 1972.2. & 3.2086 & 5.9000 & 10.264 \\
\hline 1972.3. & 3.2588 & 5.8500 & -17.099 \\
\hline 1972. & 3.6108 & 5.4800 & 2.3691 \\
\hline 1972.5 & $3.40 \leq 7$ & 5.5300 & 28.315 \\
\hline 1972.6 & 3.6108 & 5.5100 & -5.3738 \\
\hline 1972.7. & 3.7114 & 5.8600 & 21.839 \\
\hline 1972.8 & 3.6108 & 5.7300 & $6=6631$ \\
\hline 1972.9. & $4.516 \dot{3}$ & 5.7000 & $-21 \cdot 536$ \\
\hline 1572.10 & 4.5673 & 5.3500 & $1: .458$ \\
\hline 1972.11. & 4.5169 & 5.7300 & 22.418 \\
\hline 1972.12 & 4.9201 & 5.5300 & -35.681 \\
\hline 1973.1 & 4.9201 & 5.8300 & -153.58 \\
\hline 1973.2 & 5.2731 & 6.8500 & $-2 \cdot 9669$ \\
\hline 1973.3 & 5.7272 & 0.8300 & 5.6566 \\
\hline 1973.4. & 6.1312 & 6.3500 & -3.8250 \\
\hline 1973.5 & 0.0807 & 6.8800 & $-21 \cdot .920$ \\
\hline 1973.6 & 6.7376 & 7.0300 & $-8 \cdot 7952$ \\
\hline 1973.7 & $7.5+72$ & 7.0900 & $-73 \cdot 158$ \\
\hline 1973.8 & 8.3578 & 7.5700 & 38.542 \\
\hline 1973.9 & 8.6621 & 7.3100 & 42.572 \\
\hline 1973.10. & 7.2435 & 7.0200 & $-38 \cdot 08 y$ \\
\hline 1573.11. & $7 \cdot 29+1$ & 7.2700 & 24.210 \\
\hline 1973.12 & $7 \cdot 2+35$ & 7.1100 & -28.911 \\
\hline 1974.1. & $7 \cdot 3+7$ & 7.0000 & $-12 \cdot 162$ \\
\hline 1974.2 & $7.2+35$ & 7.3300 & $-1 t .524$ \\
\hline 1974.3 & $7.5+72$ & 7.4900 & -47.010 \\
\hline 1974.4. & 8.3578 & 7.5000 & -49.025 \\
\hline 1974.5 & 8.8650 & 8.1200 & $8 \cdot 3+28$ \\
\hline 1974,6 & 7.6484 & 8.0600 & .41162 \\
\hline 1974.7 & 7.9510 & 3.0600 & -39.171 \\
\hline 1974.8 & 8.3071 & 8.3200 & $-28 \cdot 765$ \\
\hline 1974.9 & 3.5758 & 8.5100 & 17.109 \\
\hline 1974.10 & 7.0411 & 8.3900 & 60.419 \\
\hline 1974.11. & $7.0+11$ & 8.0000 & 38.824 \\
\hline 1974.12 & $7 \cdot 29+1$ & 7.7500 & 15.602 \\
\hline 1975.1 & 7.0411 & 7.6500 & $2 \cdot 1235$ \\
\hline 1975.2 & 5.4244 & $7.6+00$ & 8.2741 \\
\hline 1975.3 & 4.0177 & 7.0000 & $-5 E .117$ \\
\hline 1975.4 & 5.3134 & 8.0100 & $-48 \cdot 800$ \\
\hline 1975.5 & 5.0204 & 8.3500 & 30.542 \\
\hline 1975.6 & 4.9705 & 8.1700 & 33.492 \\
\hline 1975.7 & 5.6263 & 7.0700 & $-15 \cdot 832$ \\
\hline 1975.8 & 6.0807 & 8.0900 & -38.885 \\
\hline 1975.9 & 5.9292 & 8.3600 & -15.745 \\
\hline 1975.10 & 6.2322 & 8.4800 & 71.920 \\
\hline 1975.11 & 5.2226 & 8.0200 & $-12 \cdot 349$ \\
\hline 1975.12 & 5.0209 & 8.1200 & 47.023 \\
\hline
\end{tabular}




\begin{tabular}{|c|c|c|c|}
\hline $\begin{array}{l}1976.1 \\
1976.2\end{array}$ & $\begin{array}{l}5.0209 \\
4.4162\end{array}$ & $\begin{array}{l}7.8300 \\
7.8500\end{array}$ & $\begin{array}{r}-.22014 \\
11.007\end{array}$ \\
\hline 1976.3 & 4.7689 & 7.8000 & -12.115 \\
\hline 1976 & 4.7689 & 7.9000 & $-4.4+20$ \\
\hline 1976 & 4.7689 & 7.9500 & -22.567 \\
\hline 1976 & 5.3235 & 8.1200 & 24.001 \\
\hline 1976.7 & 5.2731 & 7.9800 & -1.8370 \\
\hline 1976.8. & 5.0209 & 8.0100 & 27.223 \\
\hline 1976.9 & 5.0209 & 7.8500 & 13.431 \\
\hline 1976.10 & 5.0713 & 7.7600 & 10.282 \\
\hline 1976.11 & 4.7185 & 7.7300 & 40.877 \\
\hline 1976.12 & 4.3658 & 7.4800 & $51 \cdot 582$ \\
\hline 1977.1 & +.1644 & 7.1600 & $-75 \cdot 764$ \\
\hline 1977.2 & 4.5073 & 7.6800 & -5.9750 \\
\hline 1977 & 4.4766 & 7.7400 & 10.837 \\
\hline 1977.4. & 4.5572 & 7.6900 & 4.6471 \\
\hline 1977. 5. & 4.4162 & 7.6800 & 7.8077 \\
\hline 1977.6 & $4.768 \mathrm{~s}$ & 7.0500 & 25.600 \\
\hline 1977. & 4.9705 & 7.5000 & $-15 \cdot 646$ \\
\hline 1977 & 5.2731 & 7.6200 & $19.00 \mathrm{~s}$ \\
\hline 1977.9 & 5.3235 & 7.5100 & -12.959 \\
\hline 1977.10 & 5.8787 & 7.6100 & $-27 \cdot 040$ \\
\hline 1977.11 & 6.0807 & 7. 3000 & 9.2924 \\
\hline 1977.12 & 5.5758 & 7.7 כט ט & $-28 \cdot 118$ \\
\hline 1978.1. & 5.7777 & 7.9500 & -19.032 \\
\hline 1978.2 & 5.9796 & 8.0900 & -8.4921 \\
\hline 1978.3 & 6.0807 & 8.1600 & -16.056 \\
\hline 1978. 4 & $6 \cdot 4343$ & 8.2300 & -2.6982 \\
\hline 1978.5 & 6.1817 & 8.3100 & $-22 \cdot 105$ \\
\hline 1978.6 & 6.4343 & 8.4700 & $-22 \cdot 198$ \\
\hline 1978.7 & 6.5354 & 8.6300 & 12.697 \\
\hline 1978.8 & 6.5354 & 8.5600 & 29.288 \\
\hline 1578.9. & 7.6484 & 8.3800 & $-28 \cdot 046$ \\
\hline 1978.10 & 7.8510 & 8.5700 & $-43 \cdot 205$ \\
\hline 1978.11. & 8.8650 & 8.8600 & 19.685 \\
\hline 1478.12 & 8.8143 & 8.7300 & -34.920 \\
\hline 1979.1 & 8.8650 & 8.9600 & 18.270 \\
\hline 1979.2 & $9.47+2$ & 8.8400 & $-38 \cdot 499$ \\
\hline 1979.3 & 9.3726 & 9.0900 & $11 \cdot 334$ \\
\hline 1979.4. & 9.6266 & 9.0100 & -30.909 \\
\hline 1979.5 & 9.4742 & 9.2100 & 23.970 \\
\hline 1879.6 & 9.6774 & 9.0500 & 40.267 \\
\hline 1379.7. & 8.7635 & 8.7800 & -19.674 \\
\hline 1979.8 & 9.0173 & 8.4100 & $-22 \cdot 827$ \\
\hline 1978.9 & 10.033 & 9.0600 & $-35 \cdot 809$ \\
\hline 1979.10 & 10.186 & 0.2900 & -190.22 \\
\hline 1979.11 & 11.611 & 10.540 & 68.601 \\
\hline 1979.12 & 10.237 & 10.080 & -3.1858 \\
\hline 1980.1 & 10.084 & 10.100 & $-152 \cdot 96$ \\
\hline 1980.2 & 11.509 & 11.110 & $-176 \cdot 09$ \\
\hline 1980.3 & 13.142 & 12.270 & -20.562 \\
\hline 1980. & 15.241 & 12.400 & 237.58 \\
\hline 1980.5 & 9.8293 & 10.810 & 76.711 \\
\hline 1980.6. & 7.5472 & 10.310 & 48.201 \\
\hline 1980.7. & 6.1817 & 10.010 & -97.651 \\
\hline 1980.8 & 7.2941 & 10.680 & -95.064 \\
\hline 1980.9. & 9.0680 & 11.330 & -73.469 \\
\hline 1980.10 & 10.745 & 11.830 & $-70 \cdot 102$ \\
\hline 1980.11. & 11.306 & 12.300 & .94453 \\
\hline 1980.12. & $15 \cdot 190$ & $12 \cdot 300$ & 48.607 \\
\hline
\end{tabular}




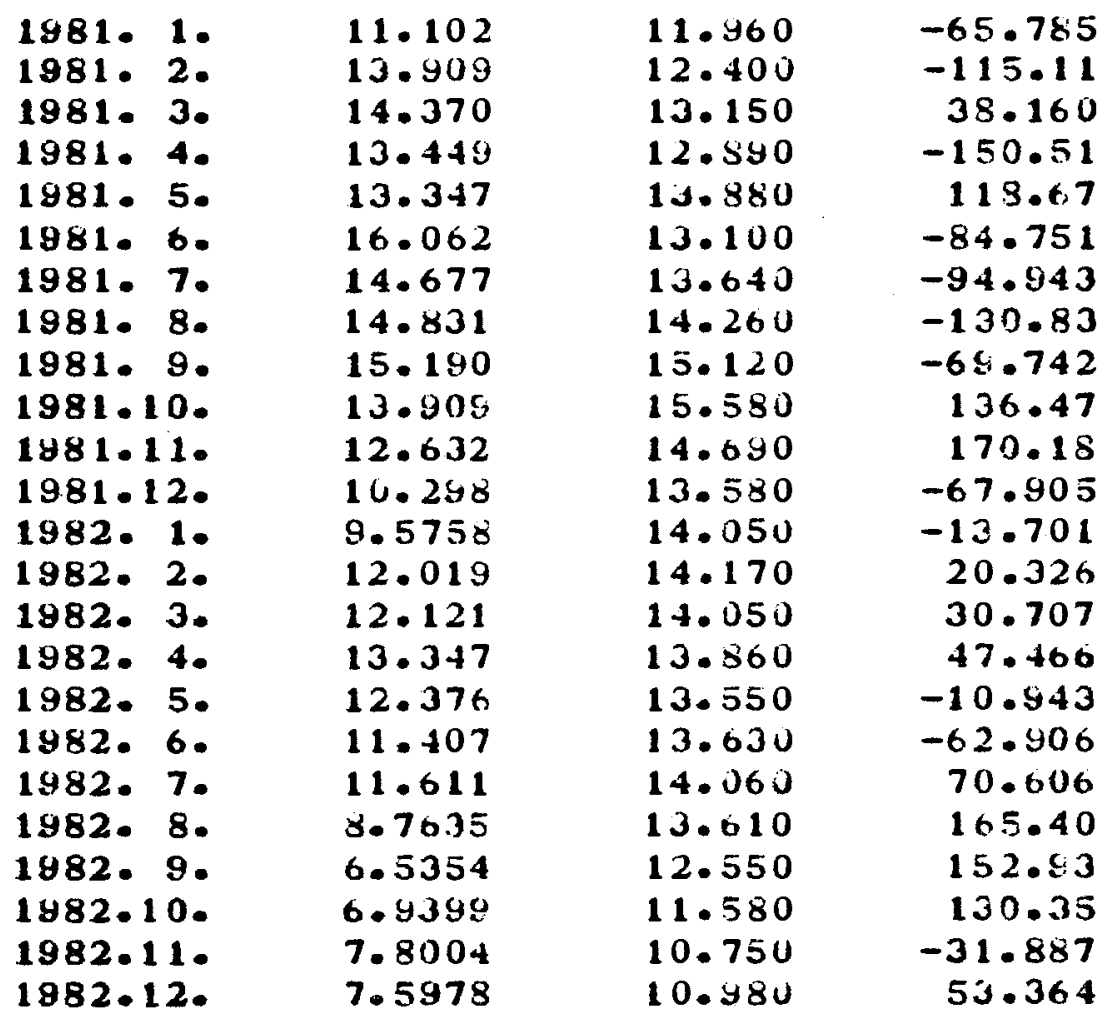

